\title{
Originals
}

\section{Protective effect of vitamin E supplementation on increased thermal stability of collagen in diabetic rats}

\author{
Y. Aoki, Y. Yanagisawa, K. Yazaki, H. Oguchi, K. Kiyosawa and S. Furuta \\ Second Department of Internal Medicine, Shinshu University School of Medicine, Matsumoto, Japan
}

\begin{abstract}
Summary. Products similar to non-enzymatic glycation end products are known to arise from the interactions between proteins and lipid peroxides in vitro. In this study, we assessed the effect of vitamin E, which possibly modifies lipid peroxide, on advanced glycation end products or similar products in vivo by measuring the fluorescence and thermal rupture time of tail tendon collagen in streptozotocin-induced diabetic rats. The diabetic rats and non-diabetic rats were fed a vitamin $\mathrm{E}$ supplemented diet, and a control diet starting 3 days after the streptozotocin injection. After the 4-week treatment, the serum lipid peroxide levels expressed as thiobarbituric acid reactants in the diabetic rats on control diet $(15.9 \pm 2.6 \mu \mathrm{mol} / 1[\mathrm{SEM}])$ were significantly $(p<0.05)$ higher than in the non-diabetic rats $(7.9 \pm 1.3 \mu \mathrm{mol} / \mathrm{l}$ on control diet and $3.3 \pm 0.4 \mu \mathrm{mol} / 1$ on supplemented diet), but the levels in the diabetic rats on supplemented diet $(7.9 \pm 2.3 \mu \mathrm{mol} / \mathrm{l})$ were reduced to the normal levels. No significant differences were found in serum glucose and glycated haemoglobin levels within the diabetic rats on control and supplemented diets. Both the fluorescence and thermal rupture time of col-
\end{abstract}

lagen were significantly $(p<0.05)$ increased in the diabetic rats on both diets compared with those in the corresponding non-diabetic rats. Although there was no significant difference in the collagen-linked fluorescence within the diabetic rats on control and supplemented diets, the thermal rupture time was significantly $(p<0.01)$ shortened with supplemented diet $(10.8 \pm 0.7 \mathrm{~min}$ on supplemented diet vs $15.0 \pm 0.7 \mathrm{~min}$ on control diet). The effect of vitamin $E$ on the thermal rupture time was not observed in non-diabetic rats $(6.6 \pm 0.5 \mathrm{~min}$ on supplemented diet vs $6.2 \pm 0.5 \mathrm{~min}$ on control diet). These results indicate that the formation of advanced glycation end products or similar products seen in hyperglycaemia can be partially inhibited by vitamin E supplementation by lowering lipid peroxide levels or oxidative stress. This study is thought to be the first to show vitamin $\mathrm{E}$ as an anti-oxidant agent limiting the formation of advanced glycation end products or similar products in vivo.

Key words: Non-enzymatic glycation, thermal stability of collagen, tail tendon, vitamin E, oxidative stress.
The action of non-enzymatic glycation on proteins, particularly advanced glycation end products (AGE) has been of considerable interest in the development of many complications in patients with diabetes mellitus. As AGE are thought to accumulate on long-lived proteins such as collagen, alterations in the solubility, fluorescence and thermal stability of collagen presumably derived from $A G E$ have frequently been assessed as indicators of the extent of AGE [1-8]. On the other hand, products similar to AGE are known to arise from the interactions between proteins and free radicals or lipid peroxide [914]. Hicks et al. [13] demonstrated in vitro that the thermal stability of non-enzymatically glycated collagen was increased after treatment with decomposing lipid peroxide, the increase of which was much greater than that of the normal collagen after the same treatment. Considering also the recently proposed concept of autoxidative glycation [15] or glycoxidation [16], it is necessary to as- sess the associations between AGE and oxidative reactions.

In this study, we designed an in vivo experiment to assess whether or not a similar phenomenon as observed in vitro by Hicks et al. [13] also occurs in vivo. We found a partial but significant inhibition of the increase in thermal stability of the tail tendon collagen by vitamin E supplementation in diabetic rats. To our knowledge, this study is the first to show vitamin $E$ as an anti-oxidant agent [17] limiting the formation of $\mathrm{AGE}$ or similar products in vivo.

\section{Materials and methods}

\section{Animals and procedure}

Male Wistar rats aged 6 weeks weighing about $110 \mathrm{~g}$ were rendered diabetic by a single streptozotocin (STZ) injection of $60 \mathrm{mg} / \mathrm{kg}$ via the tail vein. Three days after the STZ injection the diabetic rats were divided in to two groups, and were fed a vitamin E supplemented diet 
and control diet, respectively. Simultaneously, non-treated nondiabetic rats were also divided and fed the same two diets. The control diet consisted of $36 \%$ corn starch, $25 \%$ vitamin free casein, $10 \%$ alpha wheat starch, $8 \%$ purified fibre, $6 \%$ inorganic salts, $5 \%$ fine granulated sugar, $2 \%$ vitamin mixture including $2 \mathrm{mg}$ of alpha-tocopheryl acetate (2 IU of biological vitamin E activity) per $100 \mathrm{~g}$ of diet and $8 \%$ stripped com oil. The vitamin E supplemented diet contained $58.5 \mathrm{mg}$ of alpha-tocopheryl nicotinate ( $50 \mathrm{IU}$ of biological vitamin $\mathrm{E}$ activity) per $100 \mathrm{~g}$ of the above- described diet. These diets were kindly provided by Eisai Co. (Tokyo, Japan).

The diets were served daily so that each rat could eat about $30 \mathrm{~g}$ of the feed per day. After 4 weeks on these diets, both the nondiabetic and diabetic rats were weighed, and killed by the withdrawal of blood from the abdominal aorta under ether anaesthesia after an 8-h fast. These blood samples were used for several measurements, and the tails of the rats were removed and stored frozen at $-60^{\circ} \mathrm{C}$ until being used for the measurements of fluorescence and thermal stability of the tail tendon collagen.

\section{Assessment of collagen-linked fluorescence}

The fluorescence of the collagen in the tail tendons was determined according to the method of Monnier et al. [4] with minor modifications. Tail tendons were removed, and approximately $3 \mathrm{mg}$ was finely minced in phosphate-buffered saline. After centrifugation at $1500 \times g$ for $10 \mathrm{~min}$, the pellet was washed with distilled water, lipids were then extracted from the pellet with $5.0 \mathrm{ml}$ of chloroform-methanol (2:1) overnight. The sample was rehydrated by adding $2.0 \mathrm{mI}$ of methanol and $0.5 \mathrm{ml}$ of distilled water. After centrifugation, the pellet was washed twice with methanol, three times with distilled water, twice with $0.02 \mathrm{~mol} / 1 \mathrm{Hepes}$ buffer ( $\mathrm{pH} 7.5$ ) containing $0.1 \mathrm{~mol} / \mathrm{l} \mathrm{cal}-$ cium chloride (buffer $\mathrm{H}$ ), and was stored overnight at $4^{\circ} \mathrm{C}$ in buffer $\mathrm{H}$. The buffer was then removed, and the pellet was resuspended in $3.5 \mathrm{ml}$ of buffer $\mathrm{H}$ containing 1200 units of type VII collagenase (Sigma, St Louis, Mo., USA). Digestion was carried out with $4 \mu \mathrm{l}$ each of chloroform and toluene to prevent bacterial growth for $48 \mathrm{~h}$ at $37^{\circ} \mathrm{C}$ with mild shaking. A blank containing collagenase in buffer $\mathrm{H}$ was included. The digest was centrifuged at $1500 \times \mathrm{g}$ for $30 \mathrm{~min}$, and the clear supernatant containing digested collagen was used for assays of fluorescence and hydroxyproline content. About 10-30\% of the samples remained undigested, but without obvious differences within the four groups.

Fluorescence was measured against distilled water at $440 \mathrm{~nm}$ upon excitation at $370 \mathrm{~nm}$, and was corrected for the collagenase blank, using an FP-550 spectrofluorometer (Japan Spectroscopic Co., Tokyo, Japan). One hundred microlitres of digest was acidhydrolyzed in $5.0 \mathrm{ml}$ of $6 \mathrm{~mol} / \mathrm{l}$ hydrochloric acid for $24 \mathrm{~h}$ at $110^{\circ} \mathrm{C}$. The hydrochloric acid was evaporated, and hydroxyproline was measured in the dry residue according to the method of Maekawa et al. [18]. Fluorescence data were expressed as arbitrary units per $\mu$ mol hydroxyproline.

\section{Assessment of thermal stability of collagen}

The thermal stability of collagen was assessed by measuring the thermal rupture time of collagen fibres according to the method of Yue et al. [1] with minor modifications. Tendons were removed from the tails, and collagen fibres were obtained by gentle teasing of the tendons. The collagen fibres were cut in 5 -cm lengths weighing 2.0 $2.5 \mathrm{mg}$. Each fibre was suspended by a clip with a weight of $5 \mathrm{~g}$ at tached, and was immersed in a glass tube containing $7 \mathrm{~mol} / \mathrm{h}$ urea kept in a water bath maintained at $40^{\circ} \mathrm{C}$. Three collagen fibres from the tail tendons of each rat were studied, and the mean breaking time was taken as the thermal rupture time. The mean coefficient of variation of measurements in triplicate was $21.9 \%$.

\section{Other measurements}

Using the blood samples obtained from the abdominal aorta, serum glucose levels were measured by the glucose oxidase method, and glycated haemoglobin $(\mathrm{Hb})$ levels were measured by boronate af- finity chromatography [19]. Serum lipid peroxide levels were determined as thiobarbituric acid reactant (TBAR) levels by the method of Yagi [20] with malondialdehyde as standard. Serum alpha-tocopherol levels were measured by HPLC [21].

\section{Statistical analysis}

Data are presented as mean \pm SEM. Statistical analysis was done using Student's $t$-test, with a $p$ value of less than 0.05 considered significant.

\section{Results}

Body weight and biochemical data taken 4 weeks after the start of vitamin $\mathrm{E}$ supplemented diet and control diet in the non-diabetic and diabetic rats are shown in Table 1. The serum glucose and glycated $\mathrm{Hb}$ levels were significantly higher in the diabetic rats than in the non-diabetic rats. Levels of serum glucose and glycated $\mathrm{Hb}$ in the diabetic rats on the vitamin $\mathrm{E}$ supplemented diet were lower than those on the control diet, but not significantly.

The serum alpha-tocopherol levels of rats on the vitamin $E$ supplemented diet were significantly higher than those on the control diet in each of the non-diabetic and diabetic rats. The levels in diabetic rats were higher than those in the non-diabetic rats on each diet presumably due to the increased intake of vitamin $E$ per weight or the increase in serum lipid levels in diabetic rats or both. Corresponding to the alpha-tocopherol levels, the serum TBAR levels with the vitamin $E$ supplemented diet were significantly lower than those with the control diet in each of the non-diabetic and diabetic rats $(p<0.01$ and $p<0.05$, respectively). The TBAR levels were elevated in the diabetic rats on the control diet, but the levels in the diabetic rats on the vitamin E supplemented diet were reduced to the levels of the non-diabetic rats on the control diet.

The collagen-linked fluorescence levels in the tail tendons were significantly higher in the diabetic rats than in the non-diabetic rats on each diet, but there were no significant differences within the non-diabetic and within the diabetic rats on both diets. Although the tail tendon samples were not digested completely, the fluorescence measured was significantly $(p<0.001)$ correlated with the hydroxyproline concentrations in both the non-diabetic $(r=0.84)$ and diabetic $(r=0.95)$ rats.

Figure 1 shows the thermal rupture time of collagen fibres from the tail tendons in the four groups. The thermal rupture time increased significantly $(p<0.01)$ in the diabetic rats compared with that in the non-diabetic rats on each diet $(15.0 \pm 0.7$ vs $6.2 \pm 0.5 \mathrm{~min}$ on the control diet; $10.8 \pm 0.7 \mathrm{vs} 6.6 \pm 0.5 \mathrm{~min}$ on the vitamin E supplemented diet). Within the non-diabetic rats on both diets there was no significant difference, but within the diabetic rats there was a significant difference $(p<0.01)$. Therefore, the increase in the thermal rupture time as found in the diabetic rats on the control diet was partially inhibited by the vitamin E supplemented diet.

\section{Discussion}

Serum levels of lipid peroxide measured as TBAR are known to increase in diabetes [22-25]. Therefore, if lipid peroxide also accelerates the alterations in collagen as an 
Table 1. Data after 4 weeks on the vitamin $\mathrm{E}$ supplemented diet and control diet in non-diabetic and diabetic rats

\begin{tabular}{|c|c|c|c|c|}
\hline & \multicolumn{2}{|c|}{ Non-diabetic rats } & \multicolumn{2}{|c|}{ Diabetic rats } \\
\hline & Control & Supplemented & Control & Supplemented \\
\hline $\bar{n}$ & 6 & 6 & 8 & 8 \\
\hline Serum glucose $(\mathrm{mmol} / 1)$ & $8.1 \pm 0.8$ & $8.8 \pm 0.8$ & $28.5 \pm 2.0^{\mathrm{d}}$ & $25.9 \pm 1.0^{\mathrm{d}}$ \\
\hline Glycated $\mathrm{Hb}(\%)$ & $4.3 \pm 0.3$ & $4.6 \pm 0.4$ & $13.9 \pm 0.7^{\mathrm{d}}$ & $12.2 \pm 0.7^{\mathrm{d}}$ \\
\hline \multicolumn{5}{|l|}{ Collagen-linked fluorescence } \\
\hline  & $29.4 \pm 1.7$ & $25.5 \pm 2.0$ & $38.7 \pm 1.9^{c}$ & $38.1 \pm 3.0^{\mathrm{d}}$ \\
\hline
\end{tabular}

${ }^{\mathrm{a}} p<0.05,{ }^{\mathrm{b}} p<0.01$ vs the control diet in each of non-diabetic and diabetic rats; ${ }^{\mathrm{c}} p<0.05,{ }^{\mathrm{d}} p<0.01$ vs the corresponding diet in non-diabetic rats. Mean \pm SEM; TBA, Thiobarbituric acid; AU, arbitrary units

indicator of $\mathrm{AGE}$ in vivo as demonstrated in vitro by Hicks et al. [13], lipid peroxide should be taken into account when AGE is assessed in diabetes. In the present study, the serum TBAR levels were found to rise in the diabetic rats, but were reduced to the levels of the non-diabetic rats by the vitamin Esupplementation without significant differences in serum glucose and glycated $\mathrm{Hb}$ levels. In non-diabetic rats, serum TBAR levels also decreased with the vitamin E supplementation without changes in serum glucose and glycated Hb levels. Using the rats in which serum lipid peroxide levels were different under the same hyperglycaemic environment, we assessed the changes in the fluorescence and thermal stability of the collagen in the tail tendons usually used as a measure of AGE.

The collagen-linked fluorescence increased with hyperglycaemia, but no significant changes were found with the vitamin $\mathrm{E}$ supplementation in either nondiabetic or diabetic rats. On the other hand, although the thermal rupture time of collagen fibres also increased with hyperglycaemia, the increase was observed to be partially but significantly inhibited by the vitamin $\mathrm{E}$ supplementation. The effect of the vitamin E supplementation on the thermal rupture time was not found in non-diabetic rats. These results on the thermal rupture time of collagen were very similar to the observation in vitro by Hicks et al. [13] that the thermal rupture time was much longer in the nonenzymatically glycated tail tendon collagen treated with decomposing lipid peroxide than in the normal tail tendon collagen with the same treatment.

Since the thermal rupture time of collagen is thought to reflect the extent of covalent cross-linking $[3,26]$, from the present results it is inferred that the collagen-linked fluorescence cannot reflect the cross-linking of collagen satisfactorily. In fact, some reports have demonstrated that collagen-linked fluorescence is not consistent with the extent of the cross-linking of collagen [7,27]. Alternatively, the collagen-linked fluorescence measured by the method used here may be less sensitive to the changes in the crosslinking of collagen related to AGE or similar products compared with the thermal rupture time of collagen. Another possibility is that vitamin $E$ affected exclusively nonfluorescent [28] or lysyl oxidase-mediated [29] cross-linking of collagen which was suggested to increase in diabetes.
The effect of vitamin $\mathrm{E}$, which could modify lipid peroxide, on the thermal rupture time of collagen was observed only in diabetic rats, suggesting that non-enzymatically glycated collagen is more susceptible to lipid peroxide than normal collagen as demonstrated in vitro by Hicks et al. [13]. Since the formation of AGE is known to be stimulated by oxygen and catalysts of oxidation reactions [30], it is possible that the vitamin E supplementation inhibited not only the products similar to AGE derived from the interactions between lipid peroxide and collagen but the formation of AGE per se directly or indirectly despite no change in hyperglycaemia. The influence of vitamin $\mathrm{E}$ on lysyl oxidase-mediated cross-linking of collagen is not excluded, but further studies are needed to clarify this.

Ceriello et al. [31] demonstrated that early non-enzymatic glycation assessed by glycated $\mathrm{Hb}$ and proteins was inhibited by the vitamin $\mathrm{E}$ administration in diabetic patients. However, we did not observe a significant change in glycated $\mathrm{Hb}$ with vitamin E supplementation. One reason for the difference in the effect of vitamin $\mathrm{E}$ on glycated $\mathrm{Hb}$ in hyperglycaemia might be that the fasting glucose levels in our diabetic rats were more than $20 \mathrm{mmol} / \mathrm{l}$, which were much higher than those of approximately $9 \mathrm{mmol} / \mathrm{l}$ in the diabetic patients of Ceriello et al. [31].

Although it has already been reported that the cyclooxygenase inhibitors $[27,32]$ and aminoguanidine $[5,33]$ inhibited the increase of AGE or similar products with hyperglycaemia in vivo, the present study is thought to be the first to show vitamin $E$ as an anti-oxidant agent inhibiting the formation of $\mathrm{AGE}$ or similar products in vivo. Baynes [16], however, speculates that the effect of cyclooxygenase inhibitors on the thermal rupture time of collagen may result from their anti-oxidant activity. $\mathrm{He}$ presumes that anti-oxidant agents could limit the damage to proteins (fragmentation, fluorescence or cross-linking of proteins) through the inhibition of increased oxidative stress induced by both carbohydrate-dependent and lipiddependent mechanisms. The present study indicates that the formation of AGE or similar products seen in hyperglycaemia can be partially inhibited by vitamin $E$ supplementation by lowering lipid peroxide levels or oxidative stress. 


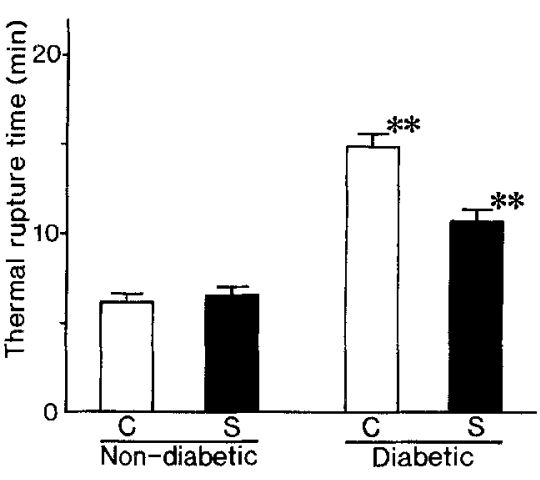

Fig. 1. Thermal rupture time of collagen fibres from the tail tendons after 4 weeks on the vitamin $E$ supplemented diet (S) and control diet (C) in non-diabetic rats $(n=6$ each) and diabetic rats $(n=8$ each). Mean $+\mathrm{SEM} ; * * p<0.01$ vs non-diabetic rats on the corresponding diet. There was no significant difference between $\mathrm{C}$ and $\mathrm{S}$ in non-diabetic rats, but a significant difference $(p<0.01)$ was found between $\mathrm{C}$ and $\mathrm{S}$ in diabetic rats

\section{References}

1. Yue DK, McLennan S, Delbridge L, Handelsman DJ, Reeve T, Turtle JR (1983) The thermal stability of collagen in diabetic rats: correlation with severity of diabetes and non-enzymatic glycosylation. Diabetologia 24:282-285

2. Monnier VM, Kohn RR, Cerami A (1984) Accelerated age-related browning of human collagen in diabetes mellitus. Proc Natl Acad Sci USA 81: 583-587

3. Kohn RR, Cerami A, Monnier VM (1984) Collagen aging in vitro by nonenzymatic glycosylation and browning. Diabetes 33 : $57-59$

4. Monnier VM, Vishwanath V, Frank KE, Elmets CA, Dauchot P, Kohn RR (1986) Relation between complications of type I diabetes mellitus and collagen-linked fluorescence. $\mathrm{N}$ Engl $\mathrm{J}$ Med 314: 403-408

5. Brownlee M, Vlassara H, Kooney A, Ulrich P, Cerami A (1986) Aminoguanidine prevents diabetes-induced arterial wall protein cross-linking. Science 232: 1629-1632

6. Suarez G, Rajaram R, Bhuyam KC, Oronsky AL, Goidl JA (1988) Administration of an aldose reductase inhibitor induces a decrease of collagen fluorescence in diabetic rats. $\mathrm{J}$ Clin Invest 82:624-627

7. Brennan M (1989) Changes in solubility, non-enzymatic glycation, and fluorescence of collagen in tail tendons from diabetic rats. J Biol Chem 264: 20947-20952

8. Dominiczak MH, Bell J, Cox NH et al. (1990) Increased collagen-linked fluorescence in skin of young patients with type I diabetes mellitus. Diabetes Care 13: 468-472

9. Davidkova E, Svadlenka I (1975) Interactions of malonaldehyde with collagen. IV. Localisation of malonaldehyde binding site in collagen molecule. Z Lebensm Untersuch-Forsch 158: 279-283

10. Kikugawa K, Kosugi H, Asakura T (1983) Effect of malondialdehyde, a product of lipid peroxidation, on the function and stability of hemoglobin. Arch Biochem Biophys 229: 7-14

11. Nair V, Cooper CS, Vietti DE, Turner GA (1986) The chemistry of lipid peroxidation metabolites: crosslinking reactions of malondialdehyde. Lipids 21: 6-10

12. Jones AF, Lunec J (1987) Protein fluorescence and its relationship to free radical activity. Br J Cancer 55 [Suppl VIII]: 60-65

13. Hicks M, Delbridge L, Yue DK, Reeve TS (1989) Increase in crosslinking of nonenzymatically glycosylated collagen induced by products of lipid peroxidation. Arch Biochem Biophys 268: 249-254

14. Fujimori E (1989) Cross-linking and fluorescence changes of collagen by glycation and oxidation. Biochim Biophys Acta 998: $105-110$
15. Hunt JV, Dean RT, Wolff SP (1988) Hydroxyl radical production and autoxidative glycosylation. Glucose autoxidation as the cause of protein damage in the experimental glycation model of diabetes mellitus and aging. Biochem J 256: 205-212

16. Baynes JW (1991) Perspective in diabetes. Role of oxidative stress in development of complications in diabetes. Diabetes 40: 405-412

17. Tappel AL (1972) Vitamin E and free radical peroxidation of lipids. Ann NY Acad Sci 203: 12-28

18. Maekawa T, Rathinasamy TK, Altman KI, Forbes WF (1970) Changes in collagen with age-I. The extraction of acid soluble collagens from the skin of mice. Exp Gerontol 5: 177-186

19. Yue DK, McLennan S, Church BD, Turtle JR (1982) The measurement of glycosylated hemoglobin in man and animals by aminophenyl boronic acid affinity chromatography. Diabetes 31 : $701-705$

20. Yagi K (1976) A simple fluorometric assay for lipoperoxide in blood plasma. Biochem Med 15:212-216

21. Ikenoya S, Abe K, Tsuda Tet al. (1979) Electrochemical detector for high-performance liquid chromatography. II. Determination of tocopherols, ubiquinones and phylloquinone in blood. Chem Pharm Bull (Tokyo) 27: 1237-1244

22. Nishigaki I, Hagihara M, Tsunekawa H, Maseki M, Yagi K (1981) Lipid peroxide levels of serum lipoprotein fractions of diabetic patients. Biochem Med 25: 373-378

23. Jennings PE, Jones AF, Florkowski CM, Lunec J, Barnett AH (1987) Increased diene conjugates in diabetic subjects with microangiopathy. Diabetic Med 4: 452-456

24. Hiramatsu K, Arimori S (1988) Increased superoxide production by mononuclear cells of patients with hypertriglyceridemia and diabetes. Diabetes 37: 832-837

25. Velazquez E, Winocour PH, Kesteven P, Alberti KGMM, Laker MF (1991) Relation of lipid peroxides to macrovascular disease in Type 2 diabetes. Diabetic Med 8: 752-758

26. Rigby BJ, Mitchell TW, Robinson MS (1977) Oxygen participation in the in vivo and in vitro aging of collagen fibres. Biochem Biophys Res Commun 79: 400-405

27. Yue DK, McLennan S, Handelsman DJ, Delbridge L, Reeve T, Turtle JR (1984) The effect of salicylates on nonenzymatic glycosylation and thermal stability of collagen in diabetic rats. Diabetes 33: 745-751

28. Richard S, Tamas C, Sell DR, Monnier VM (1991) Tissue-specific effects of aldose reductase inhibition on fluorescence and cross-linking of extracellular matrix in chronic galactosemia. Relationship to pentosidine cross-links. Diabetes 40: 1049-1056

29. Buckingham B, Reiser KM (1990) Relationship between the content of lysyl oxidase-dependent cross-links in skin collagen, nonenzymatic glycosylation, and long-term complications in type I diabetes mellitus. J Clin Invest 86: 1046-1054

30. Kaanane A, Labuza TP (1989) The Maillard reaction in foods. Prog Clin Biol Res 304: 301-327

31. Ceriello A, Giugliano D, Quatraro A, Donzella C, Dipalo G, Lefebvre PJ (1991) Vitamin E reduction of protein glycosylation in diabetes. New prospect for prevention of diabetic complications? Diabetes Care 14: 68-72

32. Yue DK, McLennan S, Handelsman DJ, Delbridge L, Reeve T, Turtle JR (1985) The effects of cyclooxygenase and lipoxygenase inhibitors on the collagen abnormalities of diabetic rats. Diabetes 34: 74-78

33. Nicholls K, Mandel TE (1989) Advanced glycosylation end-products in experimental murine diabetic nephropathy: effect of islet isografting and of aminoguanidine. Lab Invest 60: 486-491

Received: 18 March 1992

and in revised form: 27 May 1992

Dr. Y. Aoki

Second Department of Internal Medicine

Shinshu University School of Medicine

3-1-1 Asahi

Matsumoto 390

Japan 